\title{
Transition to reality: preparing the student at Georgia Tech through an undergraduate sequence of optics laboratories
}

\section{Donald O'Shea}

Donald C. O'Shea, "Transition to reality: preparing the student at Georgia Tech through an undergraduate sequence of optics laboratories," Proc. SPIE 1603, Education in Optics, (1 March 1992); doi: 10.1117/12.57879

SPIE. Event: Education in Optics, 1991, Leningrad, Russian Federation 


\title{
Transition to reality: Preparing the student at Georgia Tech through an undergraduate sequence of optics laboratories
}

\author{
Donald C. O'Shea \\ Georgia Institute of Technology, Center for Optical Science and Engineering \\ School of Physics, Atlanta, GA 30332-0430
}

\begin{abstract}
Optics is a field that deals with sources, components, and detectors. Its practice requires that students be familiar with many techniques from the simple measurement of the radius of curvature of a lens surface with a dial gauge spherometer to the analysis of figure errors of the same surface using a phase-shifting interferometer. In this article we describe the laboratory courses available to students in the Applied Optics program in the School of Physics, which is part of the Center of Optical Science and Engineering at the Georgia Institute of Technology. The experiments and projects are intended to provide the student with experiences that will prepare them for work in optics after they graduate.
\end{abstract}

\section{INTRODUCTION}

In many schools in the United States a Bachelors degree in physics is intended as an entry to a graduate program in physics. Some years ago at Georgia Tech it was recognized that a substantial number of our students were not going on to graduate school, but entering the workplace. To better assist these students for their transition to reality, a separate degree was created that emphasized the experimental over the theoretical aspects of physics. This Bachelor of Science in Applied Physics (BSAP), and a similar Master Science in Applied Physics (MSAP) awarded at the graduate level, required greater amounts of laboratory experience than is found most physics curricula. It was then necessary for the faculty of the School of Physics to develop courses to provide that experience. Laboratories were established in those areas where faculty expertise existed. One of these areas was optics.

The Applied Optics program in the School of Physics of the Georgia Institute of Technology began in 1970 with the splitting of the single undergraduate course in optics into a sequence of four courses. The result of this first change was to increase the number of laboratory hours in the basic sequence. Although this initial modification was intended only to broaden the effort in optics at the time, the decision to increase the number of laboratory courses turned out to be a wise one. This was at a time when many schools were dropping optics for lack of interest or lack of teachers. As each set of courses has been added to the sequence, the ability of our students to gain technical experience has been increased. In this paper we review the laboratory courses in applied optics available to students at Georgia Tech. Their content and organization assist students in their transition from the teaching laboratory at Tech to the research and development laboratory of their employers.

\section{THE OPTICS PROGRAM AT GEORGIA TECH}

The Applied Optics program in the School of Physics consists of a number of courses given at the upper class (JuniorSenior) levels of a 4-year university program. At the Junior level there are lecture courses in geometrical optics and physical optics (labeled Fourier Optics in the course titles) and their accompanying laboratories. At the Senior level there are a number of specialized courses. For those in the MSAP program a 12 hour laboratory practicuum is required for the degree. The courses in optics taught in the School of Physics are listed in Table 1, along with the frequency with which they are taught, the number of lecture and laboratory hours per week, the number of academic credits (quarter system), and a short description of the course. Recently a course in photographic optics was dropped from the sequence. It had been taught as a hobby course and with the limited number of faculty in optics could not be retained. Also, an emphasis on 
photographic film as a detector is not realistic today. Some of the courses are lecture courses with a companion lab course, others have a laboratory component within the course. Beyond the listed courses, students in Applied Optics take a number of Special Problems that provide project-type experience in the optics laboratory. Some of these projects have resulted in devices that are used by others at the Institute and others have been published in physics and optics journals. 2,3

Table 1. Optics courses in the School of Physics at Georgia Tech.

\begin{tabular}{|c|c|c|c|c|c|}
\hline Title & $\begin{array}{l}\text { Frequency } \\
\text { of offering }\end{array}$ & $\begin{array}{l}\text { Lect. } \\
\text { hrs. }\end{array}$ & $\begin{array}{l}\text { Lab. } \\
\text { hrs }\end{array}$ & $\begin{array}{l}\text { Acad. } \\
\text { credits }\end{array}$ & Course Description \\
\hline $\begin{array}{l}\text { Geometrical } \\
\text { Optics }\end{array}$ & $\begin{array}{l}2 \text { times } \\
\text { each year. }\end{array}$ & 3 & 0 & 3 & $\begin{array}{l}\text { Development of optical analysis of lenses and reflectors } \\
\text { using ray tracing techniques. Image formation, stops, } \\
\text { aberrations, radiometry, and analysis of optical systems }\end{array}$ \\
\hline $\begin{array}{l}\text { Optical } \\
\text { Instruments } \\
\text { Laboratory }\end{array}$ & $\begin{array}{l}2 \text { times } \\
\text { each year. }\end{array}$ & 1 & 3 & 2 & $\begin{array}{l}\text { Use of optical instruments for the measurement of optical } \\
\text { constants. Instrumentation includes spectrometers, } \\
\text { spherometers, optical testers, and refractometers. }\end{array}$ \\
\hline Fourier Optics & $\begin{array}{l}2 \text { times } \\
\text { each year. }\end{array}$ & 3 & 0 & 3 & $\begin{array}{l}\text { Physical optics using Fresnel-Kirchhoff integral equation, } \\
\text { Abbe theory of image formation, coherence, polarization. } \\
\text { Maxwell equations as a basis for physical optics. }\end{array}$ \\
\hline $\begin{array}{l}\text { Advanced Optics } \\
\text { Laboratory }\end{array}$ & $\begin{array}{l}2 \text { times } \\
\text { each year. }\end{array}$ & 1 & 3 & 2 & $\begin{array}{l}\text { Laboratory explores more advanced optical instrumentation } \\
\text { and techniques: Fabry-Perot interferometer, acousto-optic } \\
\text { modulator, holography, and photomultiplier characteristics. }\end{array}$ \\
\hline Laser Physics & $\begin{array}{l}2 \text { times } \\
\text { each year. }\end{array}$ & 3 & 0 & 3 & $\begin{array}{l}\text { Principles of laser operation. Types of lasers. Survey } \\
\text { lectures on the application of lasers to various fields. } \\
\text { Course intended for both physics and non-physics majors. }\end{array}$ \\
\hline Optical I & $\begin{array}{l}\text { Alternate } \\
\text { years }\end{array}$ & 3 & 3 & 4 & $\begin{array}{l}\text { Principles of optical design, Gaussian beam analysis, } \\
\text { modulation, scanning, detectors. Laboratory stresses optica } \\
\text { testing. }\end{array}$ \\
\hline $\begin{array}{l}\text { Optical } \\
\text { Fabrication }\end{array}$ & inate & 2 & 6 & 4 & $\begin{array}{l}\text { Theory and practice of vacuum deposition of metal and } \\
\text { multilayer thin films and of grinding and polishing of } \\
\text { optical elements }\end{array}$ \\
\hline $\begin{array}{l}\text { Electro-optics } \\
\text { Laboratory }\end{array}$ & $\begin{array}{l}\text { Once each } \\
\text { year. }\end{array}$ & 2 & 3 & 3 & $\begin{array}{l}\text { Experiments using more fiber optics, ultra-stable lasers, } \\
\text { Nd:YAG lasers, and semiconductor diode lasers. Emphasis } \\
\text { is on measurement and analysis of device performance. }\end{array}$ \\
\hline $\begin{array}{l}\text { Optomechanical } \\
\text { Design } \\
\text { Laboratory }\end{array}$ & $\begin{array}{l}\text { Once each } \\
\text { year. }\end{array}$ & 2 & 6 & 4 & $\begin{array}{l}\text { Lectures and practice in the design of optical systems. Lab } \\
\text { practice in the use of lens design, computer-aided-drafting, } \\
\text { and spreadsheet analysis of simple optical systems. }\end{array}$ \\
\hline $\begin{array}{l}\text { Lens Design } \\
\text { Laboratory }\end{array}$ & $\begin{array}{l}\text { Once each } \\
\text { year. }\end{array}$ & 0 & 6 & 2 & $\begin{array}{l}\text { Practice in the use of several lens design programs through } \\
\text { a series of weekly exercises. }\end{array}$ \\
\hline Special Problems & As required & & $3 \mathrm{X}$ & $\mathbf{X}$ & Supervised research on practical optical problems. \\
\hline
\end{tabular}

School of Physics resources for the Applied Optics program are extensive. The equipment for optics instruction is housed in four laboratories, two equipment rooms, and a darkroom. The laboratories are the Advanced Optics Lab including a holography lab, the Optical Testing Lab, the Optical Fabrication Lab, and the Optomechanical Design Lab. The equipment each lab will be described in conjunction with the individual courses. 


\section{THE LABORATORIES}

The lectures courses will not be described here. The first two, Geometrical Optics and Fourier Optics, are standard courses in geometrical and physical optics, respectively. The other lecture course, Laser Physics, has been described in detail in the literature ${ }^{1}$.

In place of a standard form for reporting results that is common in the general physics laboratories, students in the optics laboratories report their data, analyses, and results in a laboratory notebook. They are required to adhere to standard reporting techniques including no erasure or obliteration of data and full recording of the experimental conditions. This regimen is intended to train students to provide reliable records of their work. The need for such techniques for patent protection is emphasized. In some cases, the student is asked to finish the lab report during the lab. In other cases, because of the extensive analysis, they are allowed to take the notebook home for the final write up. Students are encouraged to use computer analysis and plotting programs for presentation of data.

\subsection{Optical Instruments Laboratory}

The Optical Instruments Laboratory is intended as an introduction to the equipment and techniques of optics. It is a transitional course between the highly structured laboratories of the undergraduate general physics sequence and the upper class laboratories of the Senior year. None of the experiments listed in Table 2 is particularly difficult, although one, the measurement of the dispersion of a prism requires an ability to follow directions, interpret verniers, observe faint cross hairs in the presence of a strong background, all of those wonderful skills that are needed at one time or another to align and optimize a optical instrument. It has been my contention that those students who understand and do good experimental work on this setup will do well in an optics program. If they hate this experiment, then experimental optics is probably not their cup of tea.

Table 2. Experiments in the Optical Instruments Laboratory

\begin{tabular}{|c|c|c|}
\hline Experiment & Time (wks) & Description \\
\hline Spherometer & 1 & $\begin{array}{l}\text { Measurement of radii of curvature of several lenses. Statistical analysis } \\
\text { of results. }\end{array}$ \\
\hline Beam displacement & 1 & $\begin{array}{l}\text { Measurement of refractive index of a slab of material by displacement } \\
\text { of a laser beam at different angles of incidence. }\end{array}$ \\
\hline Dispersion of a prism & 1 & $\begin{array}{l}\text { Measurement of the dispersion of the refractive index of a prism using } \\
\text { a prism table. }\end{array}$ \\
\hline Aberrations & 1 & $\begin{array}{l}\text { Measurement of spherical aberration and coma for a large plano-convex } \\
\text { lens by multiple beam ray tracing with a laser. }\end{array}$ \\
\hline Focal Length Measurement & 1 & $\begin{array}{l}\text { Measurement of the effective focal length of a compound lens using } \\
\text { Newton's Lens equation with Ronchi ruling targets. }\end{array}$ \\
\hline Abbe refractometer & 1 & $\begin{array}{l}\text { Measurement of the refractive index of materials using an Abbe } \\
\text { refractometer. }\end{array}$ \\
\hline Optical instruments & 1 & $\begin{array}{l}\text { Demonstration of a Cassegrain telescope, a zoom lens, and a research } \\
\text { microscope. }\end{array}$ \\
\hline
\end{tabular}

Over the years, I have never been completely satisfied with this laboratory. I don't like the demonstration experiment since there are no measurements to be made. The aberration experiment should be transferred to another lab and additional precision required. If there is to be a modification in this lab, I would like it to be a change in emphasis from instrumentation to measurements of optical quantities (curvature, dispersion, refractive index, aberration). This is not a great departure from what is already in place, but it requires a modification of some experiments and generation of others. 


\subsection{Advanced Optics Laboratory}

The Advanced Optics Laboratory provides students with experience in four significant fields of optics: interferometry, holography, detection, and acousto-optics. The experiments are listed in Table 3. When the lab was created the experiments were, indeed, advanced. They no longer represent the state of optics today. They do, however, represent an advance for students in their experience. In comparison to the Optical Instruments Laboratory, the experiments require considerably more understanding of optics and skill in operating the equipment: pulse height analyzers, waveform generators, high frequency oscilloscopes, and vibration isolation systems.

Table 3. Experiments in the Advance Optics Laboratory.

\begin{tabular}{|c|c|c|}
\hline Experiment & Time (wks) & Description \\
\hline Fabry-Perot interferometer & 2 & $\begin{array}{l}\text { Alignment of a Fabry-Perot interferometer, measurement of finesse. } \\
\text { Measurement of the axial mode spacing of a helium-neon laser. }\end{array}$ \\
\hline Photomultiplier characteristics & 2 & $\begin{array}{l}\text { Pulse height analysis of the output of a photomultiplier tube. } \\
\text { Response as a function of voltage. Mapping of the sensitivity } \\
\text { variation of the photocathode surface. }\end{array}$ \\
\hline Holography & 2 & $\begin{array}{l}\text { Construction of a Michelson interferometer for measurement of the } \\
\text { temporal stability of the optical bench. Fabrication of a sine grating. } \\
\text { Fabrication of a transmission hologram. }\end{array}$ \\
\hline Acousto-optic modulation & 2 & $\begin{array}{l}\text { Measurement of the acoustic velocity of sound waves in the } \\
\text { modulator and frequency of the ultrasonic transducer. Verification of } \\
\text { the Bragg condition. Measurement of system rise times. }\end{array}$ \\
\hline
\end{tabular}

This laboratory is a good laboratory for giving a student a taste of the tools of modern optics. Through the years there have been small upgrades to various parts of the experiments, but for the most part we have left the lab alone.

\subsection{Optical Testing Laboratory}

The Optical Testing Laboratory is part of the Optical Design course. It is intended to provide the student with experience using a number of optical tests. There is one experiment, Reverse Engineering, that does not involve testing, but rather is a nod to the lecture course. It requires the student to evaluate the resolution of a microfilm reader, then take it apart, measure its design parameters, put it back together, remeasure its performance, and analyze the layout of the entire system for its measured parameters.

Table 4. Experiments in the Optical Testing Laboratory.

\begin{tabular}{|c|c|c|}
\hline Experiment & Time (wks) & Description \\
\hline Schmidt telescope & 1 & $\begin{array}{l}\text { Laser ray tracing of a Schmidt telescope with and without the aspheric } \\
\text { corrector plate. }\end{array}$ \\
\hline Zygo interferometer & 2 & $\begin{array}{l}\text { Measurement of the figure quality of plane and curved surfaces and } \\
\text { transmission quality of plates. Measurement of radius of curvature. } \\
\text { Fringe analysis. }\end{array}$ \\
\hline Modulation Transfer Function & 2 & Measurement of the MTF of several lenses. \\
\hline Resolution chart & 1 & Evaluation of several lenses with a standard resolution chart. \\
\hline Reverse engineering & 1 & $\begin{array}{l}\text { Evaluation of the performance of a microfilm reader, disassembly, } \\
\text { measurement of the design, and evaluation of the reassembled } \\
\text { instrument. }\end{array}$ \\
\hline Scanners & 1 & $\begin{array}{l}\text { Measurement of the response and errors in galvanometer and pyramidal } \\
\text { mirror scanners. }\end{array}$ \\
\hline
\end{tabular}


The recent addition of a Wyko phase shifter to the Zygo interferometer will increase the number and variety of surfaces students can test in a two-week session. The first week is needed to familiarize the student with all the options of the fringe analysis program. The Modulation Transfer Function experiment has used a system built and tested in the laboratory ${ }^{3}$. It is now being completely revised as a special project by one of our Masters candidates.

\subsection{Optical Fabrication Laboratory}

This laboratory consists of two four-week segments: thin film deposition and lens and mirror fabrication. The fabrication segment is less structured than other labs. Students work on whatever needs to be done at the time. Since I am a novice in the field of fabrication, I depend on my colleague, David Fuller, who has a great deal more experience in the fabrication of optical components for instruction in fabrication. The Optical Fabrication facility has two surplus Dama spindles for rough grinding of blanks and two 14" Strasbaugh polishers for polishing the lenses. Surfaces and assembled components are tested using a precision spherometer, a Foucault tester, and the Zygo.

The thin film deposition segment has a regular sequence of four experiments (Table 5) that progress from an introduction to the use of a vacuum system to the deposition of a multilayer thin film. The work is carried out in two 18" vacuum coaters using resistance heating of metallic boats. For substrates we use standard microscope slides because they are clean and inexpensive. A thin film analysis program is also used in the lab to assess transmission curves before deposition and after runs.

Table 5. Experiments in the Optical Fabrication Laboratory.

\begin{tabular}{|c|c|c|}
\hline Experiment & Time (weeks) & Description \\
\hline $\begin{array}{l}\text { Metallic film deposition - } \\
\text { vacuum system }\end{array}$ & 1 & $\begin{array}{l}\text { Students diagram the vacuum system they are using. They learn to } \\
\text { pump it down and deposit aluminum by heating a tungsten wire } \\
\text { wrapped with aluminum foil }\end{array}$ \\
\hline $\begin{array}{l}\text { Single layer deposition - } \\
\text { optical monitoring }\end{array}$ & 1 & $\begin{array}{l}\text { Setup and testing of an optical monitor for thickness measurement. } \\
\text { Deposition of an anti-reflection film of } \mathrm{MgF}_{2} \text {. }\end{array}$ \\
\hline $\begin{array}{l}\text { Bilayer deposition - practice } \\
\text { in deposition }\end{array}$ & 1 & $\begin{array}{l}\text { Deposition of anti-reflection V-coats and W-coats on substrates using } \\
\text { optical monitors. }\end{array}$ \\
\hline $\begin{array}{l}\text { Multilayer deposition - film } \\
\text { design }\end{array}$ & 1 & $\begin{array}{l}\text { Deposition of a high reflectance coating with alternating layers of } \\
\mathrm{MgF}_{2} \text { and } \mathrm{ZnS}\end{array}$ \\
\hline Lens and mirror fabrication & 4 & $\begin{array}{l}\text { Grinding and polishing of } 1 " \text { diameter, } 8 \text { " effective focal length } \\
\text { plano-convex lenses. Grinding, polishing, and Foucault testing of a } \\
6 " \text { parabolic mirror. }\end{array}$ \\
\hline
\end{tabular}

This is my least favorite laboratory. There are times when I would like to abandon it. You have to spend a great deal of to keep this lab going. The coaters are old and they tend to break down. I keep threatening to drop the lab, but my former students express gratitude for having taken the lab. None of them have ever ground another lens or deposited another thin film, but the experience, they say, has given them additional insights into specifying a system and understanding fabrication error. Besides, they admit, it was a lot of fun. If I had better coaters, I would think so too.

\subsection{Electro-optics Laboratory}

While there has been a lecture course on lasers for many years, it was only recently that a laboratory in electro-optics was introduced. It is what might be termed the current advanced optics lab. This laboratory (Table 6), in comparison with some of the above labs, was equipped with state of the art instruments. I believe the time is past when you can equip a lab out of hand-offs from the research laboratory. You need to have good equipment to provide students with relevant experience these days. One of the problems is that some of the equipment is so good, you have to retrieve it from the research labs before the course begins! 
Table 6. Experiments in the Electro-optics Laboratory.

\begin{tabular}{|c|c|c|}
\hline Experiment & Time (weeks) & Description \\
\hline Single mode laser & 2 & $\begin{array}{l}\text { Use of Fabry-Perot interferometer and digital storage oscilloscope to } \\
\text { study the characteristics of a three-mode laser that can be single- } \\
\text { moded by polarization selection. }\end{array}$ \\
\hline Nd:YAG laser & 2 & $\begin{array}{l}\text { Measurement and alignment of a small } 10 \mathrm{~W} \text { Nd:YAG laser. } \\
\text { Continuous-wave, frequency-doubled, and Q-switched outputs are } \\
\text { optimized and measured. }\end{array}$ \\
\hline Semiconductor diode laser & 2 & $\begin{array}{l}\text { Measurement of the power vs. current curve for a low-power laser } \\
\text { diode. Measurement of the Gaussian beam characteristics with a laser } \\
\text { beam profiler. Beam transformations with lenses. }\end{array}$ \\
\hline Fiber optics & 2 & $\begin{array}{l}\text { Measurement of the attenuation in a low loss optical fiber using the } \\
\text { cut-back method. Practice in cleaving and evaluating fibers. } \\
\text { Construction and evaluation of simple fiber sensors. }\end{array}$ \\
\hline
\end{tabular}

\subsection{Optomechanical Design Laboratory}

With the increasing sophistication of lens design programs, attention in the field of optical design has shifted from the basic shape and spacing of components to the interface of these optical designs with the real world. This is the field of optomechanical engineering. Since errors in an optical design can arise from fabrication, thermal, or vibrational sources, the corrective strategy devised by the lens design process will be preserved in a well-designed optical system only if it is properly mounted and isolated from its environment. The critical techniques that maintain system performance are the specification of the mounting and materials and the assignment of the correct tolerances based on component sensitivity.

To provide training is this critical field of optics, a course in Optomechanical Design was established. The course incorporates a computer laboratory based on applications programs in lens design, computer-aided-drafting (CAD), and spreadsheets. One of the problems that must be solved when students are exposed to a number of programs in a short period of time is how to move the student beyond the familiarization stage to the point where he or she is doing work in the subject. This problem was addressed by using application programs that are available on the Apple Macintosh, which has a common operating environment.

The lecture portion of the course addresses such topics as: optical materials, mechanical analysis of optical systems, thermal analysis, vibration isolation, lens and mirror mountings, pointing and stabilization of optical systems, system alignment and test. The laboratory portion of the course requires the student to use a state-of-the-art CAD program to apply specifications and tolerances to a series of optical design studies of increasing complexity and to evaluate them using a lens design program. From an analysis of the results of his or her design decisions, the student gains understanding into the consequences of such decisions on the overall performance of the designs. Through the interplay of $\mathrm{CAD}$ and lens design programs, a series of computer breadboarding experiments are performed that provide the student with far more opportunities to make and correct errors than could ever be had by realizing a single design in a machine and an optical shop. This practice of "computer breadboarding" is becoming a standard technique in the instruments industry.

The course begins with a series of three tutorial exercises that require modest use of each of the three applications to produce results relevant to the course. After this there are a series of problems and projects that the student must complete. The problems are single concept tasks; the projects are extended studies that sometimes involve several applications. I have not provided a table of experiments for this lab, since the number of exercises is large. On matters of computer operation and use of applications programs the students are encouraged to collaborate and solve the problems together. However, each student is responsible for his or her own solution for projects and problems. 


\subsection{Lens Design Laboratory}

This laboratory is intended to provide the student with experience on a number of different lens design programs. Currently we have MacSigma and Genii PC/Mac on Macintosh IIx's and CODE V on a Sun SparcStation IPC. The lab consists of an introductory session followed by nine exercises. The first exercise evaluates a lens from the program's library so that students become familiar with the output of first and third order results. The exercises progress through lens entry to a lens optimization with limited variables. No one will become a lens designer after this laboratory. It is intended only as an introduction to the field.

\section{SPECIAL PROBLEMS}

In addition to the laboratory experiences discussed above, students are encouraged to engage in one or more Special Problems during their time in the Applied Optics program. Some of the projects involve the design of new experiments for the laboratories, some are extensions of work done beyond the standard experiments, and some are part of ongoing research programs. Each of these projects are arranged with individual faculty advisors. Student who are doing a project with me meet together to discuss their projects. This permits them to become familiar with other projects and serves as an incentive to report on progress to their peers. Besides the group meeting students meet with faculty members whenever necessary to iron out details and discuss any difficulties.

An example of recent Special Problem is the construction of a new Modulation Transfer Function Analyzer (MTFA). The previous device relied on recording the line spread function of a lens under test on a computer memory chip used as an optical detector, reading the information into a computer, and taking the Fourier Transform of the function to produce an MTF. Because the reading of the chip had to be done in an interpreted language, the process was slow and the number of lenses that could be analyzed was small. We are replacing this system with one that uses a moving knife edge in front of a silicon detector to acquire the line spread function.

An icon-based instrumentation control and analysis language, LabView, is being used to create an MTFA out of separate components: translators, optical power meter, and component holders. The benefit of this combination of computer language and instrumentation is that it provides a great deal of flexibility in construction of an experiment and it can be self documenting. It can provide students with initial instructions on the use of the instrument, give information on the experiment, record the data, and plot of the data in several different formats. This might seem to be a throwback to the standardized forms of the undergraduate physics laboratory, but is, indeed, an advance since it allows the instructor and student to modify the instrumentation and the data collection, as needed. It serves as an introduction to an instrumentation control language being used in many industrial laboratories today. Thus, this laboratory experiment will serve both to illustrate the operation of an MTFA and also provide students with experience in the use of this new type of programming environment.

\section{PROGRAM SUPPORT}

The extensive course offerings in laboratories could not have been carried out without government assistance. Over the past two decades, three National Science Foundation (NSF) laboratory instrumentation grants have funded the major purchases that set up the each set of labs. During 1970-75 period, two NSF grants provided matching funds of $\$ 41,400$ to set up the the Optical Instruments, Advanced Optics, Optical Fabrication, and Optical Testing Laboratories. The Electro-optics Laboratory was funded entirely on internal funds (approximately $\$ 50,000$ ) from the College of Science at Georgia Tech. Most recently a matching NSF grant of $\$ 29,900$ was awarded for the Optomechanical Design Lab. This also provided equipment of the Lens Design Lab. In this era of expensive equipment we have managed through NSF grants, industrial donations and internal money to put together a fine set of laboratories. Altogether the total of all grants and matching funds is close $\$ 150,000$. To this must be added donated equipment and computer programs, which increases total to close to $\$ 200,000$. 
Maintenance of the laboratories including software updates and unusual equipment for Special Problems projects are funded with donations from our Industrial Affiliates which have included Hughes Aircraft, Eastman Kodak, Newport Corporation, and United Technologies. Without this support, it would be hard to keep the labs up to standards.

\section{CONCLUSIONS}

Starting with a set of simple experiments that measure a number of optical parameters, a student can progress to a set of four experiments that use current optical instrumentation (Fabry-Perot, photomultiplier detector, acousto-optic modulator, and holographic bench) and then a set of specialized labs in optical testing, fabrication, electro-optics, lens design, and optomechanical design. With the exception of the first laboratory, all of the labs use techniques, if not always instrumentation, that are in general use throughout the optics industry. I hope that I have demonstrated that the types of experiments are relevant to the jobs of doing optics out in the real world. Certainly our students tell us that they are well prepared for most of the situations that the encounter when they leave Tech. It is not unusual for them to become the local experts in some phase of optics as soon as they demonstrate a ready knowledge of the instrumentation or technique.

For the future, we will continue to upgrade the laboratories, introducing new experiments when needed. We do need one more laboratory, as part of a course on detectors. This laboratory should focus not on detectors, since that can be addressed in the lectures, but rather on radiometry. In consulting projects in recent years I have noted that the greatest problems involved the management, measurement, and analysis of radiation from source to detector. A radiometry laboratory would give our students additional expertise to assist them in making the transition from the academic world to the reality of a job in the field of optics.

\section{ACKNOWLEDGEMENTS}

I would like to thank Jim Stevenson and Ed Thomas, former directors of the School of Physics, for giving me a free hand to make what I could of these labs. I also thank my colleague and friend, Raj Roy, who planned of the Electro-optics Lab. My other optics colleagues in the School of Physics, Jim Gole and Kevin O'Donnell, deserve thanks for teaching these labs and turning them from single person courses to ones that are taught on a rotating basis.

Without Dave Fuller, who is our instructor in optical fabrication, our lab would would suffer greatly. Dave is the president of David Labs, a company that specializes in liquid crystal temperature sensors. Despite a full schedule he has taught the lens and mirror fabrication section of the lab every time it has been offered. I thank him for his good humor, his expertise, and his dedication.

I am grateful to Paul Forman and Carl Zanoni of Zygo Corporation for the donation of the Mark II interferometer and Jim Wyant of Wyko Corporation for the special pricing on the Phase II phase shifter. I thank our Industrial Affiliates companies for the contributions that keep these labs on track.

Finally, I want to thank all the students who have come through the labs, providing criticism when they were taking the labs and encouragement when they return to Tech to tell me of their triumphs.

\section{REFERENCES}

1. D. C. O'Shea, W. R. Callen and W. T. Rhodes, "Course on Lasers for Undergraduate Students," Am. J. of Phys. vol. 44, pp. 417-420 (1976).

2. D. C. O'Shea and L. G. Dodge, "NO 2 Concentration Measurements in An Urban Atmosphere Using Differential Absorption Techniques," Applied Optics, vol. 13, p. 1481 (1974).

3. D. C. O'Shea and A. Rakes, "A Modulation Transfer Function Analyzer Based on a Microcomputer and Dynamic RAM Chip Camera," American Journal of Physics, vol. 54, pp. 821 - 825, (1986). 